\begin{tabular}{l|l|l}
\hline \hline Vol. 27(1):75-86 & Ocean and Polar Research & March 2005 \\
\hline \hline
\end{tabular}

\title{
Article
}

\author{
음향 조사에 의한 2002/2003 하계 시기의 남극 남쉐틀랜드 \\ 군도와 남오크니섬 사이의 크릴 밀도 \\ 강돈혁 ${ }^{*} \cdot$ 신형철 ${ }^{2} \cdot$ 이윤호 1 - 김영신 ${ }^{3}$ - 김수암 ${ }^{4}$ \\ I한국해양연구원 해양생물자원연구본부 \\ 2한국해양연구원 부설 극지연구소 \\ (425-600) 경기도 안산시 안산우체국 사서함 29호 \\ 3한양대학교 과학기술대학 지구해양학과 \\ (426-791) 경기도 안산시 사1동 1271 \\ 4부경대학교 수산과학대학 자원생물학과 \\ (608-737) 부산광역시 남구 대연3동 599-1
}

\section{Acoustic Estimate of the Krill (Euphausia superba) Density between South Shetland Islands and South Orkney Islands, Antarctica, During 2002/2003 Austral Summer}

\author{
Donhyug Kang ${ }^{1 *}$, Hyoung-Chul Shin ${ }^{2}$, Yoon-Ho Lee ${ }^{1}$, Youngsin $\mathrm{Kim}^{3}$, and Suam Kim ${ }^{4}$ \\ ${ }^{1}$ Marine Living Resources Research Division Research, KORDI \\ ${ }^{2}$ Korea Polar Research Institute, KORDI \\ Ansan P.O. Box 29, Seoul 425-600, Korea \\ ${ }^{3}$ Department of Earth and Marine Science, College of Science and Technology \\ Hanyang University, Seoul 426-791, Korea \\ ${ }^{4}$ Department of Marine Biology, College of Fisheries Sciences \\ Pukyong University, Busan 608-737, Korea
}

\begin{abstract}
Acoustic survey for density and biomass estimate of Antarctic krill, Euphausia superba, was conducted in the large area between South Shetland Islands and South Orkney Islands, during November 30-December 30, 2002. Considering oceanographic and geographic properties, the study area was divided into six sub-regions. Acoustic system and frequency used in the survey were quantitative echo sounder (Simrad EK500) and 38, 120-kHz split beam transducers. In order to discriminate krill aggregations in all acoustic signal, difference of mean volume backscattering strength (AMVBS) method of the two frequencies was introduced. Averaged krill density for the overall surveyed area was $23.5 \mathrm{~g} / \mathrm{m}^{2}$, and spatially averaged estimates of krill density were $44.9 \mathrm{~g} / \mathrm{m}^{2}$ (north of the South Shetland Islands), $30.3 \mathrm{~g} / \mathrm{m}^{2}$ (Bransfield Strait), $11.3 \mathrm{~g} / \mathrm{m}^{2}$ (near the Elephant Island), $13.6 \mathrm{~g} / \mathrm{m}^{2}$ (north of the Elephant Island), $18.1 \mathrm{~g} / \mathrm{m}^{2}$ (between Elephant Island and South Orkney Islands) and $21.7 \mathrm{~g} / \mathrm{m}^{2}$ (northwest of the South Orkney Islands) at each sub-area. In the two sub-regions with surveyed area, estimated krill biomass in the north of the Elephant Island was 0.315 million tones with a CV of $18.35 \%\left(6,766\right.$ mile $\left.^{2}\right)$, and between Elephant Island and South Orkney Islands was 1.26 million tones with a CV of $9.45 \%\left(20,299\right.$ mile $\left.^{2}\right)$. As a whole, the krill density in the early summer season was low level, comparing with that of January-Febnuary. This suggested
\end{abstract}

*Corresponding author. E-mail : dhkang@kordi.re.kr 
that major krill swarms in the around South Shetland Islands were reached in the mid-summer seasons from western part of the Antarctic Peninsula, and the low krill density also affects the density variation of the krill between Elephant Island and South Orkney Islands.

Key words : 남극 크릴(Antarctic krill, Euphausia superba), 음향 조사(acoustic survey), 남쉐틀랜드 군도 (South Shetland Islands), 남오크니섬(South Orkney Islands)

\section{1. 서 론}

남극해 크릴(Antarctic krill, Euphausia superba)은 식물 플랑크톤의 포식자이며, 동시에 펭귄, 해표, 조류 등의 중 요 피식자로 남극 생태계의 먹이 체계에서 중요한 부분을 차지하고 있다(Everson 2000). 또한 크릴 자체는 자원 량 측면에서 인류의 대체 수산 자원으로 가치가 크므로 분포 위치, 자원량, 계절별 이동 특성 등 다양한 연구가 진행되 어 있다(Miller and Agnew 2000; Pauly et al. 2000). 남극 해 전체에서 크릴의 연간 생산력은 2 6억 톤 정도로 추산 되고 있으나(El-Sayed 1988), 이들 크릴은 남극해 전체에 분포하는 것이 아니라 일부 지역에 집중적으로 분포하고 있다. 이 가운데 남극 반도 북서 해역에 위치한 South Shetland 군도는 남극해에서 크릴 밀도가 높은 지역 가운 데 하나이다(Everson and Miller 1994).

Scotia Sea에서 크릴의 일반적인 이동 경로는 남극 반도 남서쪽에 위치한 Bellingshausen Sea에서 겨울을 보낸 후, 남극 환류(Antarctic Circumpolar Current, $\mathrm{ACC}$ )의 주된 이동 경로를 따라 South Shetland 군도롤 거쳐 Elephant 섬 주변과 South Orkney 군도의 북쪽을 통과하여 남위 $56^{\circ}$ 부근의 South Georgia 섬까지 이동하는 것으로 알려 져 왔다(Nicol 2003). 이 지역에서 크릴 자원량을 조사하 기 위한 첫 번째 대규모의 음향 조사는 1981/1982년에 실 시되었다. 미국을 비롯한 11 개국의 조사선이 공동으로 실 시한 조사(First Intemational Biomass Experiment; FIBEX) 에서 참가국은 유사한 음향 조사 기법을 이용하여 남극 반도, Scotia Sea, South Georgia 섬 해역에서 하계 기간에 집중적으로 크릴 자원량을 조사하였다(Trathan et al. 1995). 1990년 이후 향상된 음향 장비와 수정된 크릴의 음 향 특성(acoustic target strength)을 기반으로 새로운 크릴 현존량(standing stock) 조사가 계획되었으며, 1999/2000 년 하계 기간에 비슷한 해역(조사 면적: $2 \times 10^{6} \mathrm{~km}^{2}$ )에서 미국, 일본, 영국, 러시아 등 4개국이 동일한 음향 시스템 과 측정 변수를 이용하여 크릴 자원량 조사를 실시하였다 (CCAMLR 2000; Hewitt et al. 2004a).

CCALMR(Convention on the Conservation of Antarctic Marine Living Resources)-2000 조사는 대규모 조사 이외 에 South Shetland 군도, South Orkney 군도, South Georgia 섬 주변 지역의 음향 정선 간격을 줄이는 중규모 조사를
병행하였다. 이때 연구 결과에서 South Orkney 군도 주변 의 크릴 밀도는 다른 곳에 비해 가장 높게 나타나(South Shetland 군도; $37.7 \mathrm{~g} / \mathrm{m}^{2}$, South Orkney 군도; $150.4 \mathrm{~g} / \mathrm{m}^{2}$, South Georgia 섬; $39.3 \mathrm{~g} / \mathrm{m}^{2}$ ), 이 지역 또한 대서양 남극 해에서 중요한 크릴 분포지로 확인되었다(CCAMLR 2000). 그러나 1980년 이후 최근까지 남극해 대서양 해역 에서 크릴의 밀도 및 분포에 관한 연구는 접근의 용이성 과 생태학적 중요성에 따라 South Shetland 군도 주변과 South Georgia 섬 부근에서 집중적으로 실시되었으므로 (강 둥 1999; Hewitt and Demer 1993, 1994; Ichii et al. 1998; Murphy et al. 1998; Brierley et al. 1999; Hewitt et al. 2004a, 2004b), 상대적으로 South Orkney 군도 주변 지역의 크릴 분포는 위의 두 지역에 비해 주목 받지 못하 고 있었다.

서경 $54^{\circ}-45^{\circ}$ 에 위치한 Elephant 섬과 South Orkney 군도의 중간 지역과 South Orkney 군도 주변의 크릴 분포 는 러시아, 일본, 영국에 의해 어선 혹은 조사선을 통해 제 한적으로만 알려져 왔다(Kasatkina et al. 1997; Sushin 1998). 우리나라의 경우, 2001/2002년 음향 조사를 통해 처음으로 South Orkney 군도 주변부에 대한 크릴 조사를 시도하였으나 유빙과 조사 시간의 제한으로 중간 지대인 서경 $49^{\circ}$ 까지 일부 정선에서만 실시하였다(해양수산부 2002). 관측 당시, 크릴의 평균 밀도는 South Shetland 군 도 북쪽 지역과 비슷한 분포를 보이면서 다른 지역에 비 해 높은 밀도를 보여주고 있었다. 따라서, 대서양측 남극 해의 크릴 분포를 정확히 파악하기 위해서는 크릴의 중요 이동 경로인 Elephant 섬과 South Orkney 군도를 연결하 는 중간 지대와 South Orkney 군도 주변부에 대한 크릴 조사가 추가되어야만 한다.

한편, 동일한 지역일지라도 남극 크릴의 평균 밀도는 해양 환경(해빙의 강도, 식물 플랑크톤 양, 해류의 흐름 등)에 따라 큰 년 변동을 보여주고 있다(Hewitt et al 2003). CCAMLR-2000 조사에서 확인된 South Orkney 군도 주변부의 고밀도 크릴이 일시적인 현상인지 아니면 평균 밀도가 높은 지역인지 확인하기 위하여 지속적인 조 사가 필요하다.

본 연구에서는 이러한 연구의 필요성에 의해 South Shetland 군도와 더불어 CCAMLR-2000 조사에서 크릴의 고밀도 분포지로 새롭게 부각되고 있는 South Orkney 군 


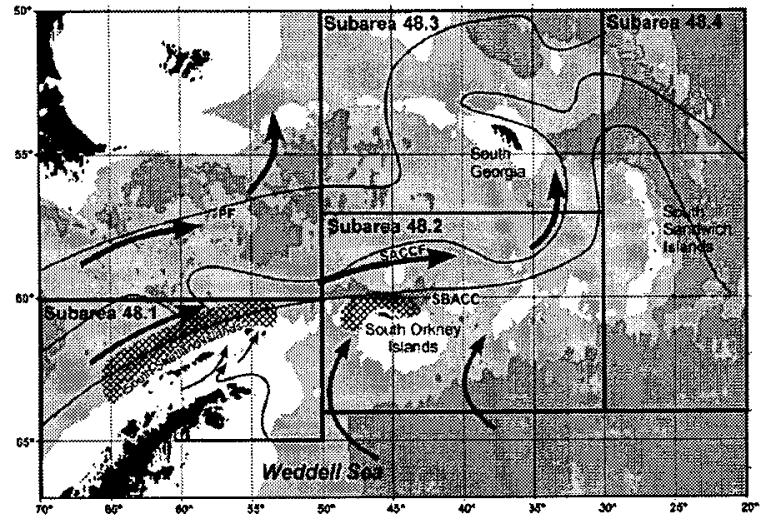

Fig. 1. Major currents and krill spawning areas (crosshatched) within the Scotia Sea. PF indicates the Polar Front; SACCF the Southern Antarctic Circumpolar Current Front; and SBACC the Southern Boundary of the Antarctic Circumpolar Current (from Hewitt et al. 2004b).

도 주변부에 이르는 넓은 해역에 대한 음향 조사를 실시 하였다. 음향 조사를 이용하여 지리적으로 분리된 각 해역 의 평균 밀도를 계산하였으며, 이를 바탕으로 조사 해역간 시·공간 크릴의 분포 특성과 현존랑을 예측하였다. 연속 적인 음향 자료를 근거로 한 South Shetland 군도와 South Orkney 군도 주변부의 광범위한 크릴 분포 규명은 이 지 역의 해양 생태계를 해석하는 하나의 자료로 사용될 수 있을 것이다.

\section{2. 재료 및 방법}

음향 조사는 South Shetland 군도 서쪽 지역인 Livingston 섬의 북서쪽 $\left(62^{\circ} \mathrm{W}\right)$ 에서 South Orkney 군도 섬 북서쪽 $\left(46^{\circ} \mathrm{W}\right)$ 에 이르는 넓은 지역에 걸쳐 2002년 11월 29 12월 30 일까지 2002/2003 남극 하계 기간동안 실시되었다. 조 사 시기 동안 음향 조사는 일정한 해역 내에서 복수의 음 향 정선, 혹은 하나의 정선에서 이루어졌으며, 총 음향 정 선 거리는 약 2,900 마일이다.

연구 지역은 극전선(Polar Front, PF)과 남극 대륙 사이 에서 남극 대륙을 중심으로 서쪽에서 동쪽으로 흐르는 대 규모의 $\mathrm{ACC}$ 가 존재하는 해역으로, 남극 순환류 남쪽 전 선(Southern Antarctic Circumpolar Current Front, SACCF), 남극 순환류의 남쪽 경계류(Southern Boundary of the Antarctic Circumpolar Current, SBACC)가 존재하고 있 다(Fig. 1, Hewitt et al. 2004b). 한편, 유입 경로가 다른 해류로 남극 반도 동쪽의 Weddell Sea에서 유입되는 해 류가 연구 지역으로 유입되고 있다. SBACC는 South Shetland 군도, Elephant 섬 북쪽, South Orkney 섬의 북

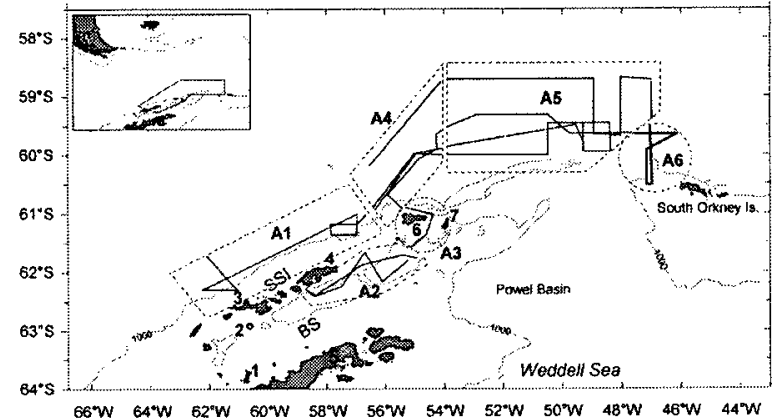

Fig. 2. Acoustic transects conducted during 2002/2003 austral summer. Regions from $\mathrm{A1}$ to $\mathrm{A6}$ indicate separated sub-area. (1-Trinity island, 2-Deception island, 3-Livingston island, 4-King George island, 5-Antarctic Peninsula, 6-Elephant island, 7-Clarence island, SSI-South Shetland Islands, BS-Bransfield Strait).

쪽에 존재하고, 남쪽에는 남극 반도 서쪽에서 유입되는 해류와 Weddell Sea에서 외해로 나오는 해류가 존재하고 있다.

조사 지역의 면적이 넓고, 크릴 이동 경로가 해류 흐름 과 직접적인 상관성을 가지고 있으며, 또한 지리적으로 해 류 유입 경로가 다른 점을 고려하여 전체 음향 자료를 해 역별 조사 구역으로 세분화 시켰다(Fig. 2). 세분화된 지역 가운데 음향 정선의 수가 3 개 미만인 지역은 평균 밀도 만을, 그 이상의 정선이 있는 지역에서는 평균 밀도 이외 에도 면적을 고려한 현존량을 추정하였다.

\section{크릴 밀도 비교를 위한 해역의 세분화}

\section{South Shetland 군도 복족(AI)}

King George 섬 북동쪽에서 Livingston 섬 북서쪽에 이 르는 해역으로 대륙 사면쪽으로 $\mathrm{SBACC}$ 의 영향이 직접적 으로 미치는 지역이다. 따라서 $\mathrm{SBACC}$ 를 따라 외해로 이 동하는 크릴이 대륙 사면, 연안쪽으로 이동하여 하계 기간 동안 고밀도의 크릴이 관측되고 있다. 음향 조사는 수심 $1000 \mathrm{~m}$ 의 대륙사면을 따라 하나의 단일 정선예서 실시되 었으며, 관측 거리는 344 마일이었다.

\section{Bransfield 해협(A2)}

Bransfield 해협은 Deception 섬과 남극 반도를 통과하 는 연안류와 Weddell Sea에서 나오는 연안류의 영향이 큰 지역으로, SBACC가 영향을 미치는 South Shetland 군도 북쪽과는 다른 해양 환경을 보이고 있다. Deception 섬과 Trinity 섬을 통과한 해류는 South Shetland 군도 남쪽의 급경사 지역을 통과하여 Elephant 섬 남쪽으로 이동하며 (Meng et al. 2002) 따라서 남극 반도 연안을 따라 이동하 는 크릴은 이 해류의 움직임을 따라 Elephant 섬 남쪽 해 
역으로 이동하게 된다. 음향 조사는 기지로 이동하는 조사 선의 경로를 따라 두 개의 정선으로 구성되었으며, 관측 거리는 333마일이었다.

\section{Elephant 섬 주변(A3)}

South Shetland 군도 북쪽과 Bransfield 해협으로부터 유입되는 해류는 Elephant 섬 주변에서 서로 만나 소규모 와류(small-scale eddy)와 같은 복잡한 해양 환경을 만들 어 낸다(강과 김 1998), 이 지역으로 유입된 크릴은 이러 한 환경에 의해 일정 시간 동안 머물 수 있게 되며, 따라 서 섬 주변은 고밀도의 크릴이 매년 형성되는 특징을 가 지고 있다(Hewitt and Demer 1994). 이 지역의 음향 자료 는 하나의 단일 정선에서 기록하였으며, 관측 거리는 74 마일로 전 조사 지역 중 가장 짧은 거리이다.

\section{Elephant 섬 복족 외해(A4)}

South Shetland 군도로 이동한 크릴의 일부는 Elephant 섬의 연안으로 유입되고, 일부는 Elephant 섬 북쪽 해역을 통과하여 북동쪽으로 이동하므로 이 지역을 통과한 음향 정선을 따로 분리하여 South Shetland 군도의 크릴 밀도 와 비교하기 위해 하나의 독립된 지역으로 분류하였다. 이 지역은 4회의 음향 조사가 이루어졌으므로 현존량을 추정 하였다. 음향 관측 거리는 총 552 마일이었다.

\section{Elephant 섬 - South Orkney 군도 중간(A5)}

Elephant 섬 주변을 통과한 크릴이 계속 북동쪽으로 이 동할 가능성을 가지고 있으므로 South Orkney 군도에 도 달하기 이전의 중간 지역으로 보고 하나의 조사 지역으로 분리시켰다. 이 지역은 4 회의 음향 조사가 이루어졌으므 로 현존량을 추정하였다. 음향 관측 거리는 총 1,097 마일 이었다.

\section{South Orkney 군도 북서 해역(A6)}

South Orkney 군도 주변의 크릴 밀도를 보기 위하여 대 륙 사면의 일부 부분이 포함되는 북서 해역을 분리시켰 다. 음향 정선은 두 개의 정선으로 구성되었으며, 음향 관 측 거리는 충 321 마일이었다.

\section{시간에 따른 크릴 밀도 변화}

남극 대륙을 따라 서쪽에서 동쪽으로 흐르는 SACCF, $\mathrm{SBACC}$ 를 따라 크릴이 이동하므로 크릴 밀도는 동일한 해역이라도 시기에 따라 크릴 밀도의 변화를 가져올 수 있다(Hewitt et al. 2004b). 음향 조사가 실시된 11월 말 은 일반적으로 크릴이 남극 반도 서쪽으로부터 South Shetland 군도로 이동을 시작하는 시기이고, 12 월 중순 이후 에는 Elephant 섬을 통과해 South Orkney 섬 부근으로

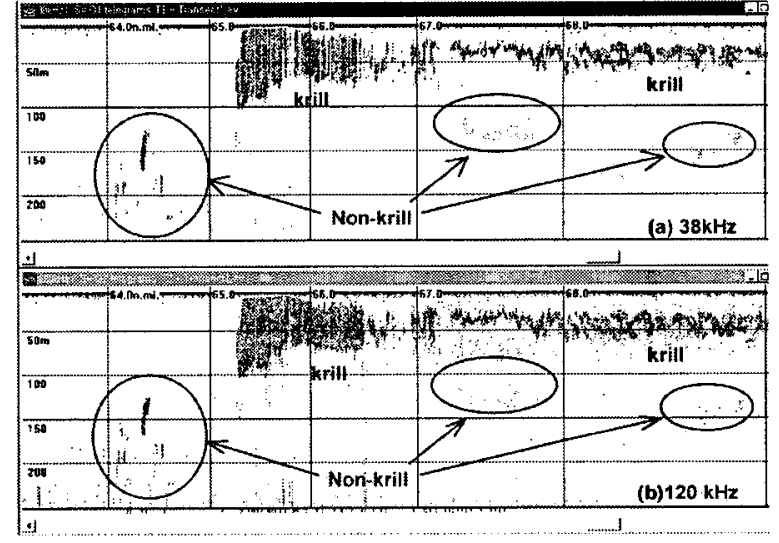

Fig. 3. Identification of krill/non-krill using mean volume backscattering strength difference ( $\triangle \mathrm{MVBS}$ ) method and virtual echogram technique.

이동하는 시기이다. 동일한 연구 해역일지라도 시기별로 크릴의 밀도가 변하므로 시간에 따른 크릴 밀도의 변화 를 비교하기 위하여 특정 해역에서 조사 시기가 다른 두 개 이상 음향 자료를 비교하였다. 이러한 비교 지역은 Bransfield 해협(A2), Elephant 섬 북쪽 해역(A4), Elephant 섬 - South Orkney 군도의 중간 해역(A5)에 해당 한다.

\section{음향 시스템 및 크릴 밀도 계산}

음향 관측을 위한 시스템은 EK-500 과학어군탐지기를 이용하였으며, 사용 센서는 split-beam 센서인 38과 120 $\mathrm{kHz}$ 를 사용하였다(SIMRAD 1997). 각 센서에 대한 입력 변수들(Sv gain, TS gain, absorption loss, 2-way beam angle, angle sensitivity, beam width)은 조사 기간 동안에 는 센서 제작사의 기본 입력 값을 사용하였으며, 후처리 과정에는 2002년 3월에 동일한 센서를 사용한 미국의 남 극 크릴 조사 팀이 실시한 보정치를 이용하였다. 이외에 보조 변수들은 CCAMLR-2000 조사에 사용한 변수와 일 치시켰다(CCAMLR 2000). 모든 음향 정선에서 ESDU (Elementary Distance Sampling Unit)는 1마일로 설정하였 다(MacLennan and Simmonds 1992).

수신된 음향 자료 가운데 크릴에 의한 신호만을 분리해 내기 위하여 기존의 시각적 분석법 대신 동일한 길이를 가진 크릴에 대한 두 개의 주파수 특성을 이용하는 평균 체적 산란 차이법(mean volume backscattering strength difference method; $\triangle \mathrm{MVBS}$ method)을 이용하였다(강 둥 2003; Watkins and Brierley 2002). 즉, 임의의 체적에서 $120 \mathrm{kHz}$ 와 $38 \mathrm{kHz}$ 의 평균 체적 산란강도(MVSV, dB) 차 이가 " $2 \mathrm{~dB}<\Delta \mathrm{MVBS}_{120 \mathrm{kz}-38 \mathrm{kHz}}<16 \mathrm{~dB}$ "을 만족하는 것 을 크릴에 의한 음향 신호로 정의하였다(Fig. 3). $\triangle \mathrm{MVBS}$ 
을 위한 자료 처리는 가상 에코그램(virtual echogram) 기 법을 사용하는 상용 프로그램인 Echoview 소프트웨어롤 이용하였으며(SonarData 2000), 적분 구간은 수면에서 $250 \mathrm{~m}$ 수심까지이다.

크릴의 음향 신호는 면적 후방산란 계수 $\left(S_{A}, \mathrm{~m}^{2} / \mathrm{mile}^{2}\right)$ 로 표시되는데 이것은 단순히 수신된 모든 신호의 합을 의미한다. 그러므로 음향 자료로부터 크릴의 절대 밀도 값을 계산하기 위해서는 크릴의 음향 산란강도(target strength, TS) 함수와 크릴의 길이-무게 함수 식을 이용하 게 된다. $38,120 \mathrm{kHz}$ 에 대한 크릴의 음향 산란강도는 CCAMLR에서 제안하고 있는 식을 이용하였다(Greene et
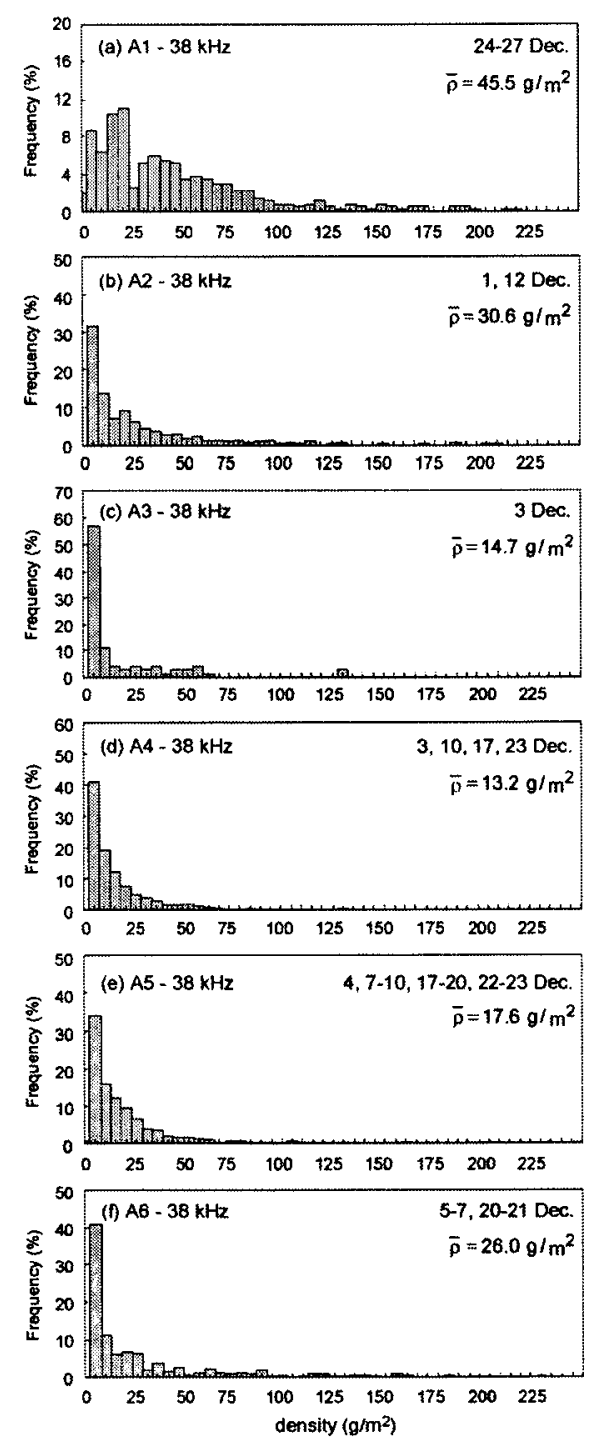

al. 1991). 연구 지역에서 크릴의 길이 및 무게는 CCAMLR -2000 조사 시기에 Scotia Sea 전역에서 실시하여 길이-무 게 함수의 대표성을 줄 수 있는 RMT8 네트의 채집 자료 를 사용하였다(CCAMLR 2000). 이때 연구 지역 대부분은 최대 길이가 $52 \mathrm{~mm}$ 에 해당하는 cluster 3 에, Bransfield 해 협과 Elephant 섬 남쪽 해역만 최대 길이가 $48 \mathrm{~mm}$ 에 해 당하는 cluster 2에 해당되었다.

크릴의 표준 길이에 대한 TS 식과 길이-무게 식으로부 터 유도되는 각 주파수의 값을 자원량 변환 계수(conversion factor, $C$ )라고 하며, 이 변환 계수와 $S_{A}$ 의 곱으로 크릴의 밀도롤 계산하게 된다(강 둥 1999). 각 주파수에
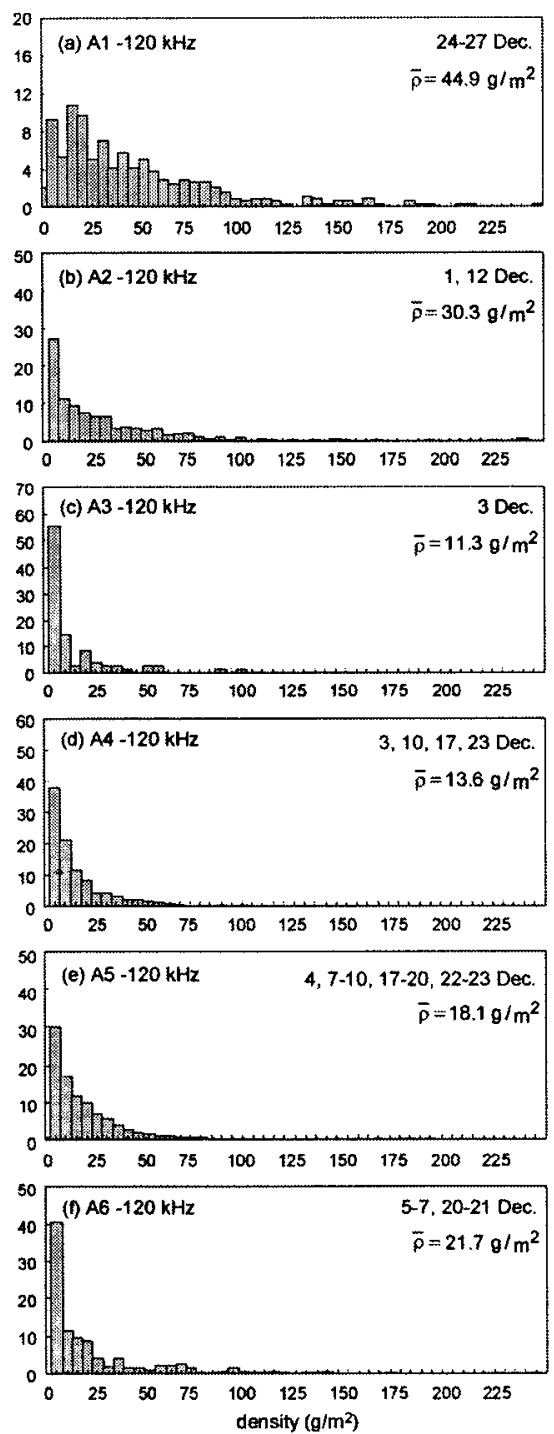

Fig. 4. Frequency of the mean density at each surveyed region for $38,120-k H z$. A krill density was calculated with ESDU of 1 mile. (A1; north of the South Shetland Islands, A2; Bransfield Strait, A3; around Elephant island, A4; north of the Elephant island, A5; intermediate between Elephant island and South Orkney Islands, A6; northwest of the South Orkney Islands). 
Table 1. Krill density and estimated biomass at each acoustic transect and survey area.

\begin{tabular}{|c|c|c|c|c|}
\hline Survey area (period) & $\begin{array}{c}\text { Distance (mile) } \\
\text { /Area (mile }{ }^{2} \text { ) } \\
\end{array}$ & $\begin{array}{c}\text { Mean density } \\
\left(\rho, g^{\prime} \mathbf{m}^{2}\right), 120 \mathrm{kHz}\end{array}$ & $\begin{array}{c}\begin{array}{c}\text { Biomass } \\
\left(\times 10^{3} \text { tone }\right)\end{array} \\
\end{array}$ & $\begin{array}{l}\text { CV } \\
(\%)\end{array}$ \\
\hline $\begin{array}{l}\text { North of the South Shetland Islands, A1 } \\
\text { (December 24-27) }\end{array}$ & 344 & 44.9 & - & - \\
\hline $\begin{array}{l}\text { Bransfield strait, } A 2 \\
\text { (December 1, 12) }\end{array}$ & 333 & 30.3 & - & - \\
\hline $\begin{array}{r}\text { Elephant Island, A3 } \\
\text { (December 3) }\end{array}$ & 74 & 11.3 & - & - \\
\hline $\begin{array}{c}\text { North of the Elephant Island, A4 } \\
\text { (December 3, 10,17, 23) }\end{array}$ & $552 / 6,766$ & 13.6 & 315.6 & 18.35 \\
\hline $\begin{array}{l}\text { Intermediated area, A5 } \\
\text { (December 4, 7-10, 17-20, 22-23) }\end{array}$ & $1,097 / 20,299$ & 18.1 & $1,260.2$ & 9.45 \\
\hline $\begin{array}{l}\text { South Orkney Islands, A6 } \\
\text { (December 5-7, 20-21) }\end{array}$ & 321 & 21.7 & - & - \\
\hline Total & 2,888 mile & 23.5 & - & - \\
\hline
\end{tabular}

대한 변환 계수는 다음의 식으로 표현된다.

$$
\begin{aligned}
& C_{38 \mathrm{kHz}}=1.424 \cdot \sum_{i=1}^{n} f_{i}\left(I_{i}\right)^{-0.274} \\
& C_{120 \mathrm{kHz}}=0.288 \cdot \sum_{i=1}^{n} f_{i}\left(I_{i}\right)^{-0.171}
\end{aligned}
$$

식에서 $f_{i}$ 는 크릴의 표준 체장 $\left(I_{i}\right)$ 의 상대 빈도수를 나타낸 다. 식 (1), (2)에 RMT8 네트 채집 자료를 이용한 크릴 길 이 분포를 넣었을 때, 변환 계수는 $38 \mathrm{kHz}$ 에서 0.4753 , $120 \mathrm{kHz}$ 에서 0.1506 이었다.

\section{3. 결 과}

2002년 11월 29 12월 30일까지 South Shetland 군도 주변, Elephant 섬과 South Orkney 군도 사이에서 실시한 음향 조사에서 $38,120 \mathrm{kHz}$ 두 주파수간의 크릴 밀도는 큰 차이를 보이지 않았다(Fig. 4). 따라서, 모든 크릴 밀도 는 남극 크릴 자원량 조사에 많이 사용되고 있는 $120 \mathrm{kHz}$ 의 자료를 이용하였다. 한편, 수신된 음향 자료로부터 1 마 일 당 크릴 밀도를 계산하였으며, 이 자료를 바탕으로 각 해역별 평균 밀도를 나타내었다.

음향 자료를 조사 해역, 해양 환경 및 크릴 분포 지역을 고려하여 총 6개의 세부 지역으로 분류했을 때, 크릴의 평 균 밀도는 South Shetland 군도 북쪽 해역에서 $44.9 \mathrm{~g} / \mathrm{m}^{2}$ 로 최대였으며, 최소는 Elephant 섬 주변에서 관측된 11.3 $\mathrm{g} / \mathrm{m}^{2}$ 였다. 이때, 전 조사 지역을 고려한 크릴의 평균 밀도 는 $23.5 \mathrm{~g} / \mathrm{m}^{2}$ 로 나타났다(Table 1). 크릴은 해류의 이동 경 로에 영향을 받으므로 각 해역별 크릴의 평균 밀도, 시간 에 따른 변화 및 분포 특성은 Fig. 1에서 보여주고 있는 해류 흐름과 연관지어 기술하였다.

\section{해역별 크릴 밀도와 분포 특성 \\ South Shetland 군도 북쪽(AI)}

음향 조사는 전 조사 지역 가운데 가장 늦은 시기인 2002년 12월 24 27일이었으며, 크릴의 평균 밀도는 44.9 $\mathrm{g} / \mathrm{m}^{2}$ 이다. 이러한 평균 밀도는 전 조사 해역 가운데 가장 높은 분포로 인접한 Bransfield 해협의 평균 밀도에 비해 약 $15 \mathrm{~g} / \mathrm{m}^{2}$, Elephant 섬 주변 보다는 약 $30 \mathrm{~g} / \mathrm{m}^{2}$ 이상 높 은 고밀도의 분포를 보여주고 있어 인접한 해역일지라도 해양 환경에 따라 크릴의 분포 밀도가 다를 수 있음을 보 여주고 있다. 크릴의 규모를 파악하기 위하여 1 마일 당 크 릴 밀도를 빈도수로 나타냈다(Fig. 4). 크릴 밀도는 15 25 $\mathrm{g} / \mathrm{m}^{2}$ 에서 최대 빈도를 나타내며, $30 \mathrm{~g} / \mathrm{m}^{2}$ 이상의 밀도는 전체 344 마일 가운데 215 마일에서 출현하여 평균 밀도에 큰 영항을 주고 있었다(Fig. 4(a)). 모든 조사 지역의 평균 밀도인 $23.5 \mathrm{~g} / \mathrm{m}^{2}$ 을 기준으로 했을 때, 평균 이하는 약 $37 \%(127$ 마일), 평균 이상은 $63 \%(217$ 마일 $)$ 였다.

Fig. 1에서 보여주는 해류의 주요 이동 경로로부터 크릴 의 이동 경로는 (1) 남극반도 서쪽 $\rightarrow$ South Shetland 군도 북부 $\rightarrow$ Elephant 섬 주변 $\rightarrow$ South Orkney 섬 (2) 남극반 도 서쪽 연안 $\rightarrow$ Bransfield 해협 $\rightarrow$ Elephant 섬 주변 (3) 남극반도 동쪽(Weddell Sea) $\rightarrow$ South Orkney 섬 (4) 남극 반도 동쪽(Weddell Sea) $\rightarrow$ Elephant 섬 주변으로 구분할 수 있다. South Shetland 군도 북부에서의 크릴 이동 경로 를 생각할 때, 12월 24 27일에 South Shetland 군도 북부 해역에서 가장 높은 크릴 밀도가 나타나고, 상대적으로 이 른 시기인 12월 초와 중순에 Elephant 섬 주변과 South Orkney 섬 주변의 크릴 밀도가 이 지역보다 낮은 것은 크 릴의 이동 시간을 고려할 때 2002/2003 하계 동안 South Shetland 군도 주변의 크릴 이동은 12 월 하순 경에 시작됨 을 나타내고 있다. 


\section{Bransfield 해협(A2)}

두 번에 걸친 모든 음향 조사로부터(12월 1일, 12 월 12 일), 전체적인 평균 밀도는 $30.3 \mathrm{~g} / \mathrm{m}^{2}$ 으로 6개 지역 가운 데 두 번째로 높게 나타났다. 1 마일 당 크릴 밀도는 전체 평균 밀도인 $23.5 \mathrm{~g} / \mathrm{m}^{2}$ 을 기준으로 했을 때, 평균 이하는 약 $55.4 \%(184$ 마일), 평균 이상은 $44.6 \%$ (149마일)였다 (Fig. 4(b)).

\section{Elephant 섬 주변(A3)}

조사 지역 가운데 가장 짧은 음향 정선으로 12 월 3일에 조사가 이루어졌다. 평균 크릴 밀도는 $11.3 \mathrm{~g} / \mathrm{m}^{2}$ 로 전 지 역 가운데 가장 낮은 분포를 보이고 있었다. 1마일 당 크 릴 밀도의 빈도수는 전체 평균에 비해 $81 \%$ 정도가 낮게 나왔으며, $10 \mathrm{~g} / \mathrm{m}^{2}$ 미만에서 최대 빈도수를 나타내 소규모 의 크릴이 분포함을 알 수 있다(Fig. 4(c)). South Shetland 군도와 Elephant 섬 주변부에 대한 크릴의 변동을 연속적 으로 파악하기 위한 CCALMR-2000 음향 조사에서(1999 년 12월 중순 2000년 3월 초순), 본 연구 시기와 시기적 으로 차이가 크지 않는 12월 중순 경에 Elephant 섬 주변 의 크릴 밀도는 약 $31 \mathrm{~g} / \mathrm{m}^{2}$ 으로 나타났으며 이러한 밀도. 분포는 3월 초순까지 지속되었다(Hewitt et al. 2004b). 따 라서, 본 연구 시기에 관측된 $11.3 \mathrm{~g} / \mathrm{m}^{2}$ 의 평균 밀도는 고 밀도 크릴이 아직 Elephant 섬 주변으로 이동하지 않았음 을 보여주고 있다.

\section{Elephant 섬 북족 외해(A4)}

이 지역은 크릴이 South Shetland 군도를 지나 SACCF 를 따라 북동쪽으로 계속 이동하는 통로로, 일주일 간격 으로(12월 3일, 10일, 17일, 23일) 조사가 이루어져 12월 전 기간에 걸친 평균 밀도 분포를 알 수 있다. 전체 정선 을 고려한 크릴의 평균 밀도는 $120 \mathrm{kHz}$ 에서 $13.6 \mathrm{~g} / \mathrm{m}^{2}$ 였 다. 1 마일 당 밀도 빈도수에서 전체 평균 이하가 $83 \%$ 를 차지하고, $15 \mathrm{~g} / \mathrm{m}^{2}$ 미만의 낮은 크릴 밀도가 전체의 $60 \%$ 를 차지해 평균 밀도 뿐만 아니라 빈도수에서 Elephant 섬 주변과 비숫한 분포를 보이고 있다(Fig. 4(d)), 이 지역 의 크릴 밀도는 해류의 이동 경로롤 따라 South Shetland 군도와 Elephant 섬의 크릴 밀도와 일정 시차를 두고 직 접적인 영향을 받게 되는데, 12 월 하순까지 밀도가 낮은 것은 이 지역까지 본격적인 크릴이 도달하지 않았음을 나 타낸다.

\section{Elephant 섬 - South Orkney 군도 중간(A5)}

음향 조사는 1,097 마일로 전 조사 지역 가운데 가장 넓 은 지역에서 이루어졌다. 4개의 정선을 모두 고려한 크릴 의 평균 밀도는 $18.1 \mathrm{~g} / \mathrm{m}^{2}$ 로 낮은 밀도 분포를 보여주고 있으나, Elephant 섬 주변과 북쪽 외해에 비해 높은 밀도

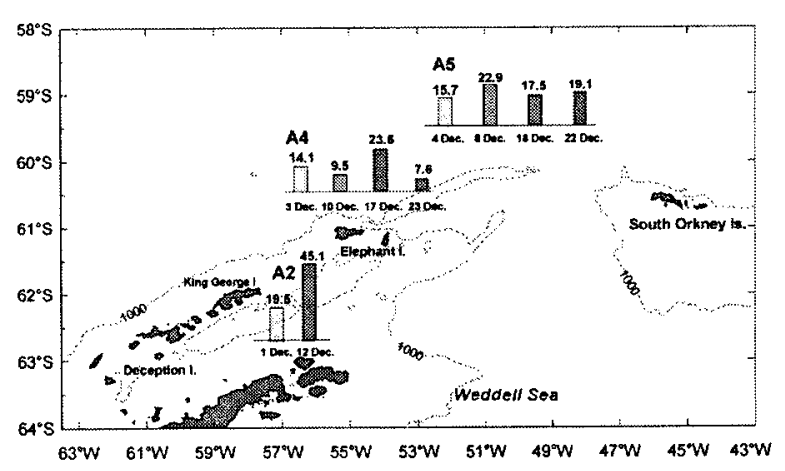

Fig. 5. Temporal variation of krill density during December 2002. (A2; Bransfield Strait, A4; north of the Elephant island, A5; intermediate between Elephant island and South Orkney Islands).

를 보이고 있다. 1 마일 당 밀도 빈도수에서 전체 평균 이 하가 70\%로 Elephant 섬 주변과 북쪽 외해에 비해 상대적 으로 고밀도 크릴이 형성되었다(Fig. 4(e)). 한편, 음향 정 선 가운데 서쪽에 위치한 Elephant 섬의 북쪽 외해보다는 동쪽 부근인 South Orkney 군도 북서쪽에서 크릴 밀도가 높게 나타나고 있었다. 이러한 밀도 분포는 Scotia Sea 전 체의 해류 흐름과 연관된 크릴 이동 방향과 12 월 중순경 의 Elephant 섬 주변에서 낮은 밀도를 고려할 때, South Shetland 군도 $\rightarrow$ Elephant 섬 주변 $\rightarrow$ South Orkney 섬의 이동 경로 보다는 남극반도 동쪽(Weddell Sea) $\rightarrow$ South Orkney 섬으로 연결되는 이동 경로로부터 크릴이 유입됨 을 암시하고 있다.

\section{South Orkney 군도 북서 해역(A6)}

음향 조사는 12월 5 7, 20 21일 사이에 실시되었으며, 관측한 자료 가운데 $\mathrm{SBACC}$ 이남인 남위 59.5 도, 서경 48 도 동쪽 지역만 이용하였다. 평균 크릴 밀도는 $21.7 \mathrm{~g} / \mathrm{m}^{2}$ 로 Elephant 섬과 South Orkney 군도의 중간 해역보다는 높은 밀도를 나타내, 이 지역의 크릴 유입 경로는 Elephant 섬 - South Orkney 군도 중간 지역과 같이 기존의 경로가 아닌 다른 유입 경로가 존재할 가능성을 나타내고 있다.

\section{크릴 밀도의 변동성}

$2002 / 2003$ 년 시기에 30 일 걸쳐 조사한 음향 정선에서 일정한 시간 차이롤 두고 동일한 해역을 2 희 이상 관측된 음향 자료만을 따로 분류하여 크릴 밀도의 비고로부터 시 간에 따른 변동성을 유추하였다(Fig. 5).

\section{Bransfield 해협(A2)}

두 번의 음향 조사는 2002년 12월 1일(193마일), 12월 12 일(140마일)로 약 12일 간의 시차가 있었다. 두 개의 정 
선을 모두 고려한 크릴 밀도는 $30.3 \mathrm{~g} / \mathrm{m}^{2}$ 이나, 이를 조사 시기별로 세분화하면 첫 번쩨 조사인 12월 1일의 평균 밀 도가 $19.5 \mathrm{~g} / \mathrm{m}^{2}$ 인 반면, 12 일 후인 12월 12일에는 $45.1 \mathrm{~g} /$ $\mathrm{m}^{2}$ 으로 평균 밀도가 약 2.3 배의 증가하였다. Fig. 1 에서 Bransfield 해협의 해류는 주로 남극 반도의 서쪽 연안으 로부터 유입되므로 이 해류를 따라 크릴의 이동을 고려할 때, 평균 밀도의 변동은 남극 하계의 중심으로 들어가면서 서쪽으로부터 크릴이 이동함을 보여주고 있다. 12월 중순 의 Bransfield 해협내의 크릴 밀도는 24 27일에 1회 실시 한 South Shetland 군도 북쪽의 평균 밀도 $\left(44.9 \mathrm{~g} / \mathrm{m}^{2}\right)$ 와 비슷하여, 2002/2003 하계 기간 중에는 12월 중순 이후에 South Shetland 군도 남북에 유사한 밀도의 크릴이 유입됨 을 알 수 있다.

\section{Elephant 섬 북쪽 외헤(A4)}

Elephant 섬 북쪽 해역의 조사는 7일 간격으로 총 4회 가 실시되었다(12월 3일, 10 일, 17일, 23일). 각 시기별로 세분하면 12 월 3 일의 첫 번째 조사에서는 $14.1 \mathrm{~g} / \mathrm{m}^{2}, 10$ 일 에는 $9.5 \mathrm{~g} / \mathrm{m}^{2}, 17$ 일에는 $23.6 \mathrm{~g} / \mathrm{m}^{2}$, 그리고 제일 마지막 조사인 23 일에는 $7.6 \mathrm{~g} / \mathrm{m}^{2}$ 로 나타났다. 평균 밀도는 최소 와 최대에서 약 3 배의 밀도 차이를 보여주고 있으나, 전체 적으로 낮은 밀도 분포를 보여 South Shetland 군도 북쪽 으로부터 이 지역까지 적어도 12 월 중순까지는 크릴의 본 격적인 이동이 진행되지 않았음을 보여주고 있다.

\section{Elephant 섬 - South Orkney 군도 중간(A5)}

Elephant 섬 북쪽과 South Orkney 군도를 연결하는 중 간 지대인 이 지역은 South Shetland 군도의 크릴이 계속 북동쪽으로 이동한다면 Elephant 섬 북쪽의 크릴 밀도와 짧은 시차를 두고 일치하는 경향을 보여야만 한다. 4희 실 시한 음향 자료를 각 시기별로 세분하면 12 월 4 일의 조사 에서는 $15.7 \mathrm{~g} / \mathrm{m}^{2}, 7 \sim 10$ 일에는 $22.9 \mathrm{~g} / \mathrm{m}^{2}, 17 \sim 20$ 일에는 $17.5 \mathrm{~g} / \mathrm{m}^{2}$, 마지막 조사인 22 23일에는 $19.1 \mathrm{~g} / \mathrm{m}^{2}$ 로 나타 났다. 크릴 밀도의 변동성은 Elephant 섬 북쪽보다 안정된 분포를 보여 South Shetland 군도 북쪽에서 크릴의 본격 적인 이동이 진행되지 않았음에도 크릴 밀도가 일정한 상 태임을 나타내고 있다. 이러한 이유로 해류의 이동 경로를 따라 Weddell Sea로부터의 직접적인 유입과 남동쪽에 위 치한 South Orkney 군도로부터의 유입을 고려할 수 있다. 즉 South Shetland 군도를 지나 이 지역으로 진입하는 크 릴이 Elephant 섬 북쪽 지역을 통과하기에는 이른 시기이 므로 또 다른 크릴 공급원으로 CCALMR-2000 음향 조사 에서 고밀도 크릴이 분포하는 지역으로 알려진 South Orkney 군도로부터 대륙 사면이 발달한 북서 방향으로 크 릴이 이동할 가능성이 있다. South Orkney 군도에 인접한 세부 지역 $\mathrm{A} 6$ 에서의 평균 크릴 밀도가 $21.7 \mathrm{~g} / \mathrm{m}^{2}$ 으로 이

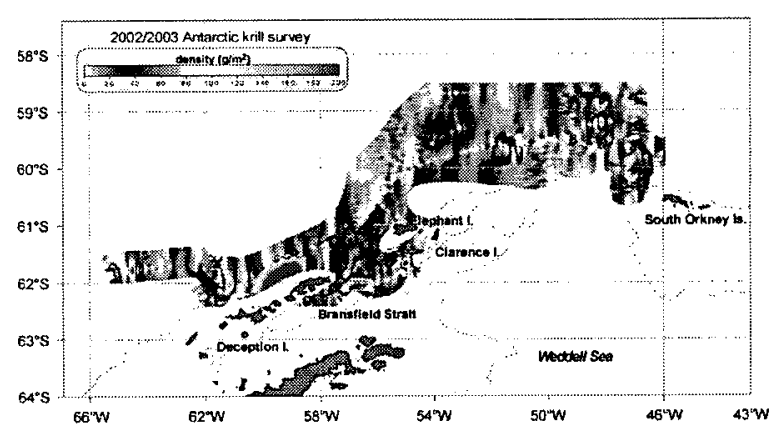

Fig. 6. Horizontal distribution of krill density between South Shetland Islands and South Orkney Islands, during December 2002. The averaged krill density for the overall surveyed area was $23.5 \mathrm{~g} / \mathrm{m}^{2}$.

지역의 전체 평균과 큰 차이를 보이지 않고, 특히 12 월 10 일 이후에는 연구 지역 $\mathrm{A} 6$ 과 거의 일치하는 양상을 보이 는 것으로 이러한 가능성을 설명할 수 있다.

\section{크릴의 공간 분포 및 예측 자원량}

2002년 12월에 South Shetland 군도 주변과 South Orkney 군도 근처에 이르는 지역에서 크릴의 공간 분포를 알아보기 위하여 모든 음향 자료를 이용한 크릴의 공간 분포를 알아보았다(Fig. 6). 크릴의 공간적인 분포는 South Shetland 군도 북쪽 해역의 일부 지역에서 가장 높 게 나타나고 있는데 이 시기는 12월 말경으로 남서쪽의 Bellingshausen Sea로부터 크릴이 본격적으로 이동하는 시 기임을 보여주며 이동 경로 또한 이 지역임을 보여주고 있다.

Bransfield 해협 북동쪽에서는 규모는 크지 않으나 고밀 도 분포가 King George 섬 남동쪽과 Elephant 섬 남쪽 사 면에 나타나고 있다. Elephant 섬 주변부에서 크릴은 이전 연구 결과에서 12 월 중순 경에 평균 밀도가 약 $31 \mathrm{~g} / \mathrm{m}^{2}$ 로 높은 분포를 나타냈으나(Hewitt et al. 2004b), 2002/2003 시기에는 고밀도의 크릴이 형성되지 않았다. 이러한 가능 성은 Elephant 섬 주변 해역의 낮은 밀도 $\left(11.3 \mathrm{~g} / \mathrm{m}^{2}\right)$ 를 고 려한다면 적어도 12 월 10 일 이전에는 고밀도의 크릴이 Elephant 섬까지 도달하지 않음을 의미한다. 한편, Elephant 섬과 South Orkney 군도를 연결하는 중간 지대와 South Orkney 군도 북서쪽의 공간 분포는 일부 지역에서 $50 \mathrm{~g} / \mathrm{m}^{2}$ 이상의 높은 밀도를 보여주고 있으며, 특히 South Orkney 군도에 가까울수록 고밀도 크릴이 차지하는 범위 가 증가하고 있다.

South Shetland 군도를 지나는 크릴이 Elephant 섬을 통 과하여 Scotia Sea로 이동할 때의 경로를 공간 밀도 분포 에서 암시하고 있다. Elephant 섬 북서쪽에서 섬 쪽에 근 접한 사면 지역에서는 $50 \mathrm{~g} / \mathrm{m}^{2}$ 의 고밀도인 반면, 외해로 
나가면 크릴 밀도가 $20 \mathrm{~g} / \mathrm{m}^{2}$ 미만을 나타내 크릴의 이동 통로가 외해가 아닌 Elephant 섬에 가까운 북쪽 사면임을 나타내고 있다.

전체 연구 지역 가운데 일정한 조사 면적을 포함하는 지역은 Elephant 섬 북쪽 해역(A4)과 Elephant 섬과 South Orkney 군도를 연결하는 중간 지역(A5)이다. 총 4 개의 정선으로 구성된 Elephant 섬 북쪽 해역의 조사 면적 은 약 $6,766 \mathrm{mile}^{2}$ 로, 평균 밀도는 $13.6 \mathrm{~g} / \mathrm{m}^{2}$ 이다. 이 지역 에서 $120 \mathrm{kHz}$ 음향 자료로부터 추정된 크릴 자원량은 315 천 톤으로 변량 계수는 $18.35 \%$ 이다(Table 1). 한편, Elephant 섬과 South Orkney 군도를 연결하는 중간 지역 의 조사 면적은 약 $20,299 \mathrm{mile}^{2}$ 로, 평균 밀도는 $18.1 \mathrm{~g} /$ $\mathrm{m}^{2}$ 이다. 이 지역에서 $120 \mathrm{kHz}$ 음향 자료로부터 추정된 크 릴 자원량은 각각 1,260 천 톤이고, 변량 계수는 $9.45 \%$ 였 다(Table 1).

\section{4. 고 찰}

남극 반도 북서쪽에 위치한 South Shetland 군도와 Elephant 섬 주변에서 음향을 이용한 크릴 밀도 조사는 각국 에 의해 조사 해역의 차이는 있지만 1980 년 이후 최근까 지 매년 수행되고 있다(강 둥 1999; Hewitt and Demer 1994; Ichii et al. 1998; Brierley et al. 1999; Hewitt et al. 2004b). 이와는 대조적으로 South Orkney 군도 주변은 지 리적으로 접근하기 어려운 특성으로 인해 조사가 제한적 으로 이루어져 왔다(Kasatkina et al. 1997).

King George 섬과 Elephant 섬은 약 110 마일 정도 떨어 져 있고, Bransfield 해협은 군도를 경계로 남북으로 분리

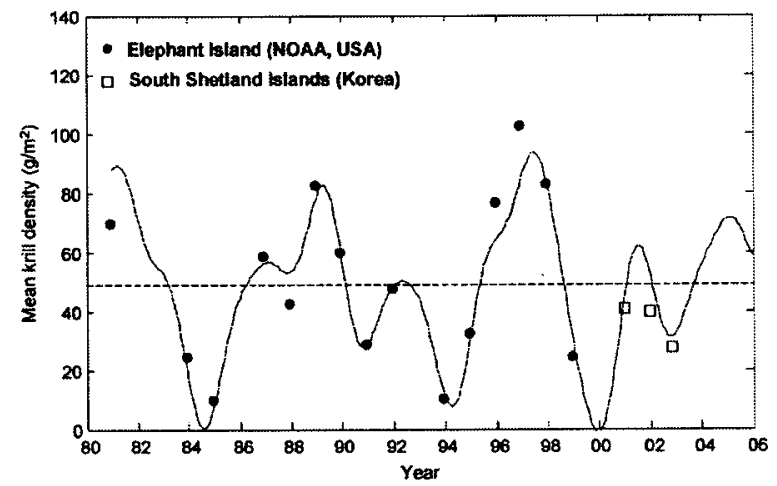

Fig. 7. Krill density estimation from numerical model. The model was made with yearly acoustic data (filled circle) near the Elephant Islands from NOAA, USA. The blank rectangular represented krill density around South Shetland Islands, which is obtained from acoustic survey of the Korea. And the dotted line indicated apparently mean krill density.
되어 있으나 지리적 인접성 때문에 크릴 음향 조사에서 지역을 분리하지 않고 하나의 지역(South Shetland 군도 전체)으로 고려하는 경우와, 각 지역을 세분화하는 경우가 있다.

음향을 이용한 South Shetland 군도 전체의 평균 밀도 는 $58.3 \mathrm{~g} / \mathrm{m}^{2}$ (Ichii et al. 1998), $49 \mathrm{~g} / \mathrm{m}^{2}$ (Hewitt et al. $2004 \mathrm{~b}$ ), $37.7 \mathrm{~g} / \mathrm{m}^{2}$ (CCAMLR 2000)로 조사되었고, Elephant 섬 주변만을 고려할 때 13화 관측한(1981 1993) 평 균 밀도는 $53.2 \mathrm{~g} / \mathrm{m}^{2}$ (Hewitt and Demer 1994), 8회 관측 한(1981 1997) 평균 밀도는 $54.7 \mathrm{~g} / \mathrm{m}^{2}$ (Brierley et al. 1999) 이다. 이를 자료를 토대로 크릴의 년 변화를 모델화 시킨 결과에서 최대 밀도는 1997 년에 약 $100 \mathrm{~g} / \mathrm{m}^{2}$ 이었으며, 큰 년 변동을 가짐을 알 수 있다(Fig. 7).

$$
\begin{aligned}
& \rho\left(g / m^{2}\right)=46.7+23.9 \cos \left(\frac{2 \pi t}{8}+5.5\right) \\
& -15.5 \cos \left(\frac{2 \pi t}{5}+0.5\right)+11 \cos \left(\frac{2 \pi t}{4}+4.3\right) \\
& \quad+12.1 \cos \left(\frac{2 \pi t}{3}+1.3\right)+4.2 \cos \left(\frac{2 \pi t}{2}+1.8\right)
\end{aligned}
$$

그러나 모델 결과로부터 Elephant 섬 주변의 외형적인 평균 밀도는 약 $50 \mathrm{~g} / \mathrm{m}^{2}$ 정도이다. South Shetland 군도 북부 해역에서 2000/2001, 2001/2002, 2002/2003 남극 하 계 기간동안 우리나라의 음향 조사를 통한 크릴 밀도를 모델 결과와 비교했을 때 유사성을 보이고 있다. 이러한 유사성은 South Shetland 군도 북부 해역의 평균 밀도는 약 $50 \mathrm{~g} / \mathrm{m}^{2}$ 정도로 유추할 수 있다.

다른 남극해의 크릴 연구와 비슷하게 두 지역의 많은 연구들도 남극 여름이 진행된 시기인 1 2월에 주로 진행 되었다. 따라서 많은 연구 결과들이 제시하고 있는 크릴의 평균 밀도 및 자원량에서 12월의 영향은 포함되지 않은 경우가 대부분이다. 특히, South Shetland 군도, Bransfield 해협, Elephant 섬 주변은 12월부터 남극 반도 서쪽의 Bellingshausen Sea로부터 크릴이 공급되므로 12월의 분 포 특성이 이해되어야만 해류의 흐름을 따라 Scotia Sea로 이동하는 크릴이 밀도를 예측할 수 있게 된다.

본 연구가 진행된 12월의 평균 크릴 밀도는 South Shetland 군도, Elephant 섬과 북부 해역에서 각각 44.9, $11.3,13.6 \mathrm{~g} / \mathrm{m}^{2}$ 로 나타났다(Table 1). 앞에서 언급한 1 2 월의 평균 밀도와 비교했을 때, South Shetland 군도의 경 우(12월 24 27일) 비슷한 밀도 분포를 보이나, Elephant 섬(12월 3일)과 북부 해역(12월 3 23일)의 경우 매우 큰 편차를 보이고 있다. South Shetland 군도에서 12월의 평 균 밀도가 1 2월보다 낮은 양상은 2000년 12월 18 21일 $\left(41.4 \mathrm{~g} / \mathrm{m}^{2}\right), 2001$ 년 12월 7 8일 $\left(9.2 \mathrm{~g} / \mathrm{m}^{2}\right), 12$ 월 22 28일 $\left(22.9 \mathrm{~g} / \mathrm{m}^{2}\right)$ 조사에서 나타나고 있으며, Elephant 섬 $(2000$ 
년 12월 22일-35.1 g/m², 2001년 12월 24 일-16.8 g/ $\mathrm{m}^{2}$ ) 부 근에서도 비슷하게 나타나고 있다(해양수산부 2001, 2002). 이러한 조사 결과들은 SACCF를 따라 South Shetland 군 도와 Elephant 섬 주변에 크릴이 본격적으로 도달하는 시 기는 12 월 하순이나 1 월 초가 될 가능성을 나타낸다. 그러 나 동일한 지역에서도 크릴 밀도의 연변동이 있으므로, 이 에 대한 지속적인 추가 조사가 필요하다.

Bransfield 해협의 크릴 밀도는 외해로 이동하는 SBACC 가 직접 영향을 미치는 South Shetland 군도 북쪽과는 Trinity 섬과 Deception 섬을 통과하는 연안류를 따라 이 동하는 크릴의 영향을 받으며, 이 크릴은 Elephant 섬 남 쪽을 거쳐 외해로 이동하게 된다. 본 조사에서는 12월 1 일 의 평균 밀도가 $19.5 \mathrm{~g} / \mathrm{m}^{2}$ 인 반면, 12 월 중순에는 $45.1 \mathrm{~g} /$ $\mathrm{m}^{2}$ 으로 증가하고 있다. 이전 조사에서도 중순 이후의 평 균 밀도는 $41.4 \mathrm{~g} / \mathrm{m}^{2}$ (2000년 12월 19일), $40.4 \mathrm{~g} / \mathrm{m}^{2}$ (12월 26 일)로 높게 나타나 Bransfield 해협의 경우에는 12월 중 순경부터 본격적인 크릴이 유입됨을 알 수 있다.

Bellingshausen Sea에서 겨울을 보낸 크릴이 South Shetland 군도 북쪽보다 Bransfield 해협에 일찍 도달하는 이유는 크릴의 이동 경로 혹은 유영 능력으로 설명할 수 있을 것이다. 즉, South Shetland 군도 북쪽에 도달하는 $\mathrm{SBACC}$ 의 이동 경로보다 연안류를 타고 오면 이동 경로 가 짧게 된다. 일반적인 크릴의 유영 능력이 $10 \sim 15 \mathrm{~cm} /$ $\sec (K i l s$ 1979) 혹은 $11 \sim 13 \mathrm{~cm} / \mathrm{sec}(S u s h i n$ 1998)로 알려졌 으므로 평균값인 $13 \mathrm{~cm} / \mathrm{sec}$ 를 고려할 때, 10 20일 정도면 112 224 km를 이동할 수 있으므로 이동 경로가 짧은 연 안류에 걸쳐 이동하는 크릴이 먼저 도달하는 것이 가능하 게 된다.

Elephant 섬과 South Orkney 군도까지 직선 거리는 약 $550 \mathrm{~km}$ 로 크릴의 유영 능력을 고려하면 Elephant 섬 근처 의 크릴이 South Orkney 군도까지 도달하는데 약 50 여 일 이 소요된다. 따라서 12월 중순 경 이들 지역에 도달하는 크릴의 유입처가 South Shetland 군도 북부라고 하면, 이 동 시간을 고려할 때 South Shetland 군도 북부 지역의 11 월 12월 초의 크릴 밀도가 이들 지역의 12 월 중순의 밀도 와 유사해야만 하는 가정이 뒤따라야 한다. 본 연구에서 관측된 이들 지역의 12월(4 22일) 평균 밀도는 $18.1 \mathrm{~g} / \mathrm{m}^{2}$ 로 12월 초에 관측된 Elephant 섬 주변(A3)과 북쪽 해역 (A4)보다 높다. 이러한 시기적인 밀도 차이는 이 지역으로 12 월에 유입되는 크릴은 일반적인 경로 이외에 다른 유입 경로를 이용할 가능성이 있음을 보여주고 있다. 2002/ 2003년 조사 지역보다 남쪽에 위치한 2000년 12월 4 8일 의 조사에서 $\left(60-61.5^{\circ} \mathrm{S}, 51-54^{\circ} \mathrm{W}\right)$ 평균 밀도는 $23.8 \mathrm{~g} / \mathrm{m}^{2}$, 2001년 12월 13 22일에 조사한 밀도는 $21.3 \mathrm{~g} / \mathrm{m}^{2}$ 으로 비 슷한 시기의 2002년 12월 중순의 Elephant 섬 연안보다 밀도가 높다(해양수산부 2001, 2002). 따라서 12월 중순에
이 지역으로 유입되는 크릴은 Bransfield 해협을 12월 중 순에 통과한 크릴일 가능성도 있다. 이러한 가능성은 올 해와 이전 연구에서 12월 중순이면 Bransfield 해협에 상 대적으로 높은 크릴이 이미 유입됨을 보여주기 때문이다. 12 월 초-중순에 이 지역에 크릴을 공급하는 또 하나의 가 능성은 Weddell Sea에서 유빙과 함께 해류의 흐름을 타 고 유입되는 크릴을 고려할 수 있다. 그러나 이러한 가능 성을 뒷받침할 만한 조사 자료는 부족한 실정으로 이 지 역의 크릴 밀도를 정확히 예측하기 위해서는 조사가 필요 하다.

South Orkney 군도 주변의 크릴 밀도는 1996년 조사 (2 3월)에서 $139.7 \mathrm{~g} / \mathrm{m}^{2}$ (Kasatkina et al. 1997), 1999/2000 년 조사(1월 28 29일)에서 $150.4 \mathrm{~g} / \mathrm{m}^{2}$ (CCAMLR 2000) 으로 매우 높은 분포 특성을 보이고 있었다. 1999/2000년 의 높은 밀도는 South Orkney 군도의 가장 큰 섬인 Coronation 섬을 가로 지르는 두 개의 정선에서 나타난 고밀 도 때문으로 올해 연구 지역과 비슷한 북서쪽 해역에서는 $23.7 \mathrm{~g} / \mathrm{m}^{2}$ 으로 큰 편차를 보이고 있지 않았다(CCAMLR 2000). 이 당시 관측 기간이 1월 하순인 것을 고려하면 북 서쪽 해역의 크릴 밀도는 12 월과 1 월 사이에서 편차를 보 이지 않음을 알 수 있다. 이 지역은 음향 조사 자로의 부 족으로 인해 군도 주변부의 고밀도 크릴과 북서 외해 지 역의 낮은 밀도가 일반적인 특성인지 아니면 큰 년 변동 을 가지는지는 추가 조사가 필요하다.

\section{5. 결 론}

South Shetland 군도와 더불어 최근에 크릴의 고밀도 분포지로 새롭게 부각되고 있는 South Orkney 군도 주변 부에 이르는 넓은 해역에 대한 크릴 음향 조사를 2002년 11월 29 12월 30일까지 실시하였다. 총 음향 정선 거리는 약 2,900마일로, 다양한 해양 환경(수심, 해류, 수괴 등)으 로 구성되어 있다. 따라서, 해역별 시·공간 특성 파악을 위하여 조사 해역을 South Shetland 군도 북쪽, Bransfield 해협, Elephant 섬 주변, Elephant 섬 북쪽 외해, Elephant 섬과 South Orkney 군도 중간 해역, South Orkney 군도 북서 해역 등 6개의 세부 지역으로 분리하였다. 또한 시간 에 따른 크릴의 변동을 비교하기 위하여 동일한 해역에서 조사 시기가 다른 두 개 이상 음향 자료를 비교하였다.

음향 관측을 위한 시스템은 EK-500 과학어군탐지기로, 사용 주파수는 split beam인 38 과 $120 \mathrm{kHz}$ 이었다. 수신된 음향 자료 가운데 크릴에 의한 신호만을 분리해 내기 위 하여 다중 주파수의 평균 체적 산란 차이법(mean volume backscattering strength difference method; $\triangle \mathrm{MVBS}$ method) 을 이용하였다.

음향 조사 결과, 전 조사 지역을 고려한 크릴의 평균 밀 
도는 $23.5 \mathrm{~g} / \mathrm{m}^{2}$ 로 나타났다. 세부 조사 해역의 평균 크릴 밀도는 $44.9 \mathrm{~g} / \mathrm{m}^{2}$ (South Shetland 군도 북쪽), $30.3 \mathrm{~g} / \mathrm{m}^{2}$ (Bransfield 해협), $11.3 \mathrm{~g} / \mathrm{m}^{2}$ (Elephant 섬 주변), $13.6 \mathrm{~g} / \mathrm{m}^{2}$ (Elephant 섬 북쪽 외해), $18.1 \mathrm{~g} / \mathrm{m}^{2}$ (Elephant 섬과 South Orkney 군도 중간 해역), $21.7 \mathrm{~g} / \mathrm{m}^{2}$ (South Orkney 군도 북서 해역)로 나타났다.

시간에 따른 크릴 밀도의 변동은 Bransfield 해협의 경 우, 12 월 초의 평균 밀도가 $19.5 \mathrm{~g} / \mathrm{m}^{2}$ 인 반면, 중순에는 $45.1 \mathrm{~g} / \mathrm{m}^{2}$ 으로 평균 밀도가 약 2.3 배의 증가하여 남극 하 계의 중심으로 들어가면서 서쪽으로부터 Bransfield 해협 내로 이동해 오는 크릴 밀도가 증가하는 것으로 나타났 다. Elephant 섬 북쪽 외해는 4회의 조사가 일주일 단위로 실시되었지만 전체적으로 낮은 밀도 분포를 보여 South Shetland 군도 북쪽에서 크릴의 본격적인 이동이 진행되지 않았음을 보여주고 있다. 한편, Elephant 섬과 South Orkney 군도 중간 해역은 4회 실시한 음향 자료에서 크릴 밀도의 변동이 Elephant 섬 북쪽보다 안정된 분포를 보여 South Shetland 군도 북쪽에서 크릴의 본격적인 이동이 진 행되지 않았음에도 크릴 밀도가 일정한 상태를 유지하고 있었다.

전체 연구 지역 가운데 일정한 조사 면적을 포함하는 지역에 대한 크릴 자원량은 Elephant 섬 북쪽 해역에서 315천 톤, Elephant 섬과 South Orkney 군도를 연결하는 중간 지역에서는 1,260 천 톤으로 예측되었다.

연속적인 음향 자료를 근거로 한 South Shetland 군도 와 South Orkney 군도 주변부의 광범위한 크릴 분포 규명 은 이 지역의 해양 생태계를 해석하는 하나의 자료로 사 용될 수 있을 것이다. 한편, 1980년 이후 현재까지 South Shetland 군도 주변에서는 연속적인 조사를 통해 크릴의 변동 특성이 많이 알려져 있으나, South Orkney 군도 주 변의 음향 조사는 제한적으로 이루어져 이에 대한 지속적 인 연구가 진행되어야 할 것이다.

\section{사 사}

본 연구는 해양수산부의 "남극해 유용생물자원 개발 연 구(PM16800, PM28700)"의 연구비로 수행되었습니다.

\section{참고문헌}

강돈혁, 김수암. 1998. $\mathrm{ADCP}$ 를 이용한 남극 크릴 분포에 관 한 연구. 한국수산자원학회지, 1(1), 67-80.

강돈혁, 신형철, 김수암, 이윤호, 황두진. 2003. 다중 주파수 의 체적산란강도 차이를 이용한 에코그램내에서의 종 분 리와 잡음 제거. 힌국수산학회지, 36(5), 541-548.

강돈혁, 황두진, 김수암. 1999. 남극 남쉐틀랜드 군도 북부 해
역의 크릴 분포 및 자원량. 한국수산학회지, 32(6), 737747.

해양수산부. 2001. 남극해 유용생물자원 개발 연구. BSPM 00068.

해양수산부. 2002. 남극해 유용생물 자원 개발 연구. BSPM 16800.

Brierley, A.S., D.A. Demer, J.L. Watkins, and R.P. Hewitt. 1999. Concordance of interannual fluctuations in acoustically estimated densities of Antarctic krill around South Georgia and Elephant Island: biological evidence of same-year teleconnections across the Scotia Sea. Mar: Biol., 134, 675-681.

CCAMLR. 2000. Report of the $B_{0}$ Workshop. WG-EMM00/21. La Jolla, USA. 70 p.

El-Sayed, S.Z. 1988. The Biomass program. Oceanus, 31, 75-79.

Everson, I. 2000. Distribution and standing, The Southern Ocean. p. 63-79. In: Krill Biology, Ecology and Fisheries. ed. by I. Everson. Blackwell Science, London.

Everson, I. and D.G.M. Miller. 1994. Krill mesoscale distribution and abundance: results and implications of research during the BIOMASS Programme. p. 129-144. In: Southern Ocean Ecology: the BIOMASS perspective. ed. by ElSayed. Cambridge University Press, Cambridge.

Greene, C.H., T.K. Stanton, P.H. Wiebe, and S. McClatchie. 1991. Acoustic estimates of Antarctic krill. Nature, 349, 110.

Hewitt, R.P. and D.A. Demer. 1993. Dispersion and abundance of Antarctic krill in the vicinity of Elephant Island in the 1992 austral summer. Mar. Ecol. Prog. Ser, 99, 29-39.

Hewitt, R.P. and D.A. Demer. 1994. Acoustic estimates of krill biomass in the Elephant Island area: 1981-1993. CCAMLR Sci., 1, 1-5.

Hewitt, R.P., D.A. Demer, and J.H. Emery. 2003. An 8-year cycle in krill biomass density inferred from acoustic surveys conducted in the vicinity of the South Shetland Islands during the austral summers of 1991-1992 through 2001-2002. Aqua. Living Resour., 16, 205-213.

Hewitt, R.P., J.L. Watkins, M. Naganobu, V. Sushin, A.S. Brierley, D.A. Demer, S. Kasatkina, Y. Takao, C. Goss, A. Malyshko, M. Brandon, S. Kawaguchi, V. Siegel, P. Trathan, J.H. Emery, I. Everson, and D. Miller. 2004a. Biomass of Antarctic krill in the Scotia Sea in January/ February 2000 and its use in revising an estimate of precautionary yield. Deep-Sea Res. II, 51, 1215-1236.

Hewitt, R.P., S. Kim, M. Naganobu, M. Gutierrez, D. Kang, Y. Takao, J. Quinones, Y.-H. Lee, H.-C. Shin, S. Kawaguchi, J.H. Emery, D.A. Demer, and V.J. Loeb. 2004b. Variation in the biomass density and dispersion of 
Antarctic krill in the vicinity of the South Shetland Islands throughout the 1999/2000 austral summer. DeepSea Res. II, 51, 1435-1456.

Ichii, T., K. Katayama, N. Obitsu, H. Ishii, and M. Naganobu. 1998. Occurrence of Antarctic krill (Euphausia superba) concentrations in the vicinity of the South Shetland Islands: relationship to environmental parameters. DeepSea Res. II, 45, 1235-1262.

Kasatkina, S.M., V.N. Shnar, M.I. Polischuk, A.M. Abramov, and V.A. Sushin. 1997. Assessment of krill flux factors in waters of the South Orkney Islands during summer 1996. CCAMLR Sci., 4, 195-206.

Kils, U. 1979. Swimming speed and escape capacity of Antarctic krill Euphausia superba. Meereforschungg, 27, 264-266.

MacLennan, D.N. and E.J. Simmonds. 1992. Fisheries Acoustics. Chapman \& Hall, London. 325 p.

Meng, Z., P.P. Niilerb, and J.-H. Huc. 2002. Surface currents in the Bransfield and Gerlache Straits, Antarctica. DeepSea Res. I, 49, 267-280.

Miller, D. and D. Agnew. 2000. Management of krill fisheries in the Southern Ocean. p. 300-337. In: Krill Biology, Ecology and Fisheries. ed. by I. Everson. Blackwell Science, London.

Murphy, E.J., J.L. Watkins, K. Reid, P.N. Trathan, I. Everson, J.P. Croxall, J. Priddle, M.A. Brandon, A.S. Brierley, and E. Hofmann. 1998. Interannual variability of the South
Georgia marine ecosystem: biological and physical sources of variation in the abundance of krill. Fish. Oceanogr., 7, 381-390.

Nicol, S. 2003. Krill and Currents-Physical and Biological Interactions Influencing the Distribution of Euphausia superba. Ocean and Polar Res., 25, 633-644.

Pauly, T., S. Nicol, I. Higginbottom, G. Hosie, and J. Kitchener. 2000. Distribution and abundance of Antarctic krill (Euphausia superba) off East Antarctica $\left(80-150^{\circ} \mathrm{E}\right)$ during the Austral summer of 1995/1996. Deep-Sea Res. II, 47, 2465-2488.

SIMRAD. 1997. Simrad EK500 Scientific Echo Sounder. Horten, Norway.

SonarData. 2000. SonarData EchoView User Guide, EchoView v. 2.10.53. SonarData Tasmania Pty. Ltd. Hobart, Australia.

Sushin, V.A. 1998. Distribution of the Soviet krill fishing fleet in the South Orkneys area (Subarea 48.2) during 1989/1990. CCAMLR Sci., 5, 51-62.

Trathan, P.N., I. Everson, D.G.M. Miller, J.L. Watkins, and E.J. Murphy. 1995. Krill biomass in the Atlantic. Nature, 373, 201-202.

Watkins, J.L. and A.S. Brierley, 2002. Verification of the acoustic techniques used to identify Antarctic krill. ICES J. Mar. Sci., 59, 1326-1336. 